\title{
Perfiles de los editorialistas de la prensa de referencia en Francia. Roles y representaciones
}

\author{
María SANTOS-SAINZ \\ maria.santos-sainz@ijba.u_bordeaux3.fr \\ Institut de Journalisme Bordeaux Aquitaine. Université Bordeaux Montaigne (Francia)
}

Recibido: 8 de febrero de 2014

Aceptado: 8 de septiembre de 2014

\begin{abstract}
Resumen
El artículo se centra en investigar los perfiles de los editorialistas de la diarios de referencia en Francia, centrándose en sus roles y representaciones. La metodología se basa en una perspectiva diacrónica y cualitativa del análisis de las entrevistas en profundidad de una hora de duración realizadas a partir de una muestra de los editorialistas de los tres diarios de referencia en Francia: Libération, Le Figaro, Le Monde. Tres editorialistas de cada periódico han sido entrevistados. El enfoque privilegia una perspectiva sociológica y socio-discursiva así como socio-organizativa de su perfil. Los resultados demuestran la importancia que juegan las predisposiciones sociales en la carrera profesional para alcanzar el puesto de editorialista. La "retorica profesional" se apoya en un discurso con representaciones míticas asentadas fundamentalmente en la función pedagógica y en menor medida en el rol democrático.

Palabras clave: editorialistas, prensa de referencia en Francia, roles profesionales, periodismo de opinión.

\section{The Profiles of the Editorialists from the Newspapers of Reference in France. Roles and Representations}

\begin{abstract}
The article analyzes the profiles of the editorialist from the newspapers of reference in France, focusing on their roles and representations. The methodology is based on a perspective diachronic and qualitative of the analysis of in depth interviews, one hour of duration, realized from a sample of the editorialist from three diaries of reference in France: Libération, Le Figaro, Le Monde. Three editorialist of every newspaper have been interviewed. The results demonstrate the importance that the social predispositions play in the professional career to reach the editorialist's position. The speech that they have is full of mythical representations main based in the pedagogic function and in minor measure in the democratic role.
\end{abstract}

Keywords: ediorialist, quality press in France, partisanship, political journalism, opinion journalism.

\section{Referencia normalizada}

SANTOS-SAINZ, María (2015): "Perfiles de los editorialistas de la prensa de referencia en Francia. Roles y representaciones”. Estudios sobre el Mensaje Periodístico. Vol. 21, Núm. 1 (enero-junio), págs.: 559-577. Madrid, Servicio de Publicaciones de la Universidad Complutense.

Sumario: 1. Introducción; 1.1. Metodología. 2. Perfiles del editorialista; 2.1. Origen social; 2.2.Diplomas; 2.3. Género; 2.4. Generaciones. 3. Percepción del Rol; 3.1. Cualidades y funciones; 3.2 Secretos de fabricación. 4. Influencia; 4.1. El auge del comentario: los "editocrates"; 4.2. Periodistas de referencia. 5. El futuro del editorial. 6. Conclusiones. 7. Referencias bibliográficas.

\section{Introducción}

Figura legendaria del periodismo de opinión, su influencia y prestigio han alimentado la mitología de la profesión. El oficio de editorialista en Francia se asocia a grandes plumas de renombre ya que algunos diarios se han acogido a la fórmula de firmar el escaparate ideológico del periódico. 
Considerados en la cima de la profesión, su función se sitúa a mitad de camino de la reflexión política, filosófica e histórica de la actualidad. Ligados a la historia de la prensa escrita, sin embargo, en la actualidad su ámbito de intervención se ha multiplicado a otros medios, en particular a la radio y a la televisión, convirtiéndose algunos editorialistas en emblemas de la elite periodística y del vedettariat mediático.

Representan a una minoría de la profesión. Menos del 3\% de los periodistas en ejercicio en Francia ocupan estas funciones. De los tres diarios de referencia franceses Le Figaro, Libération y Le Monde solamente este último no firma sus editoriales, siguiendo la tradición anglosajona. Esto explica su invisibilidad a pesar de su situación en la alta jerarquía del periódico. Es un puesto de confianza reservado a aquellos periodistas cuya trayectoria profesional es rica en capital cultural y cuentan con la legitimidad de su diario. La adscripción de su trabajo es efectuada a partir de sus competencias y de su capital simbólico acumulado.

El interés de un estudio comparativo de los editorialistas en el seno de tres ejemplos emblemáticos entre los principales periódicos de referencia en Francia, Le Monde, Le Figaro y Libération permite conocer su papel y su estatuto en el seno de la redacción. La investigación se efectúa a partir de entrevistas en profundidad a editorialistas de estos tres diarios de referencia en Francia. El enfoque privilegia una perspectiva sociológica y socio-discursiva así como socio-organizativa de su perfil.

La investigación tiene como objetivo aportar algunos elementos de respuesta a las cuestiones siguientes: ¿Quiénes son? ¿Cómo han llegado a ocupar la posición? ¿Cómo construyeron su carrera? ¿Cuáles han sido sus modos de aprendizaje y de calificación? ¿Cuáles son sus competencias?, ¿Cómo funciona la división de su trabajo con relación a los campos de especialización? Respecto a su identidad profesional, ¿Cuáles son sus representaciones y valores profesionales?, ¿Quiénes son sus periodistas de referencia?, ¿Qué futuro presagian a este género de opinión, que para alguno se encuentra en declive?

\subsection{Metodología de la investigación}

El estudio se basa en una perspectiva diacrónica y cualitativa con el análisis de las entrevistas en profundidad de una hora de duración realizadas en una muestra de los editorialistas de los tres diarios de referencia en Francia: Libération, Le Figaro, Le Monde. Tres editorialistas de cada periódico han sido entrevistados. Un cuestionario común ha sido elaborado con el fin de coordinar el conjunto del análisis de su discurso.

\section{Perfiles del editorialista}

\subsection{Origen social}

El estudio de la individualidad periodística como objeto de las Ciencias Sociales ha cobrado un gran relieve en estos últimos años en Francia (Lemieux, 2010; Corcuff, 2011, Martuccelli y De Singly, 2012). Partimos de la base en este trabajo de que el investigador debe tener en cuenta las predisposiciones sociales, las oportunidades de carrera, o fenómenos como la personalidad y su historia personal, la subjetividad, la autonomía y la creatividad individual en la construcción de una carrera profesional. De la misma manera conviene examinar los procesos de socialización. 
Si los estudios consagrados al origen social de la élite periodística ya apuntaban la pertenencia de sus miembros a las categorías sociales más favorecidas (Rieffel: 1981, Santos-Sainz: 2001), esta tendencia se refuerza aún más en el estudio de los editorialistas. Los hijos de obreros, artesanos, pequeños comerciantes, agricultores o hijos de inmigrantes resultan ausentes. Tampoco aparecen los hijos de otras categorías socioprofesionales intermedias como funcionarios, profesores o empleados. La selección social es tan sumamente selectiva que la pretendida democratización o diversidad de la profesión resulta, en este ámbito, un espejismo. Este fenómeno reaviva el debate sobre la falta de apertura social en la profesión en Francia (Marchetti, 2011).

\begin{tabular}{|c|c|c|}
\hline \multicolumn{3}{|c|}{$\begin{array}{c}\text { Cuadro 1. Categorías socioprofesionales a partir de la profesión } \\
\text { del padre }\end{array}$} \\
\hline Le Monde: & Le Figaro: & Libération: \\
\hline Médico & Directivo empresa & Medico \\
\hline Empresario & Abogado & Director de un hospital) \\
\hline Director banco & Directivo empresa & Directivo \\
\hline
\end{tabular}

De los nueve editorialistas entrevistados, todos ellos coinciden en acumular capital social (Bourdieu, 1970), económico y cultural (Serre, 2012). La mayoría de los editorialistas son hijos de padres con profesiones liberales (médicos y abogados, principalmente) o bien directores y ejecutivos de empresas o bancos. La herencia familiar, puede explicar en parte, junto a otros factores, la proyección de ciertos periodistas hacia la cima profesional, gracias a la posesión de conocimientos culturales, relaciones sociales o gracias al arte de saber acomodarse a ciertas situaciones que les abrirán las puertas de la información y de la respetabilidad. En este sentido, el perfil de los editorialistas responde a una procedencia netamente elitista (Ver cuadro 1).

Algunos de los editorialistas entrevistados, como Francois Sergent de Libération, reconocen la falta de diversidad y denuncian una cierta reproducción social:

"Es verdad que no hay editorialistas cuyos padres sean obreros. Pero tampoco pienso que esto pueda cambiar la línea editorial. Hoy en día hay obreros de derechas, incluso algunos votan al Frente Nacional. Es verdad que podemos denunciar la ausencia de diversidad, ya sea respecto al sexo, formación, origen social, o la inexistencia de hijos de inmigrantes. Es una calamidad. Yo lo observo en mi diario. Entre los nuevos periodistas contratados, uno es el primo de tal persona, o el hijo de un sociólogo de renombre".

\subsection{Diplomas}

El cursus de formación de los editorialistas resulta bastante homogéneo por su alta cualificación. Los estudios de larga duración (la mayoría tienen el equivalente a un máster) constituyen un indicador de un origen social favorecido. Las trayectorias atípicas (sin diplomas) han desaparecido de la morfología de la profesión y responden a épocas de antaño. Otro fenómeno emergente, análogo a la profesión, es el haber estudiado en una escuela de periodismo (Marchetti, 2011).

Si en general la tendencia en estos últimos años ha sido el incremento del número de diplomados universitarios en la profesión (de 38\% en 1964 a 69\% en 1990), la posesión de diplomas prestigiosos y títulos de postgrado universitarios es una condición 
que comparten la mayoría de los editorialistas entrevistados, donde figura incluso un doctor en Sociología.

La mitad de la muestra entrevistada ha realizado estudios de Periodismo. Todos ellos coinciden en elegir una escuela de periodismo prestigiosa, parisina y privada, donde a menudo se forja la élite periodística: el conocido Centre de Formation de Journalistes de Paris (CFJ). En este sentido, llama la atención que ninguno haya estudiado en una escuela de periodismo perteneciente a una universidad pública o incluso en una escuela situada en provincias. Y es que no es un azar que el CFJ sea la escuela de Periodismo preferida por la élite periodística (Rieffel, 1981; Marchetti, 2011). Las carreras seguidas por los editorialistas entrevistados son: Economía, Ciencias Políticas y Letras (Ver cuadro 2).

\begin{tabular}{|c|c|c|}
\hline \multicolumn{3}{|c|}{ Cuadro 2. Diplomas de los editorialistas } \\
\hline Le Monde & Libération & Le Figaro \\
\hline Escuela de periodismo CFJ & Doctor en Sociología & Máster en Ciencias Económicas \\
\hline Licenciado en Letras & Máster en Economía & Licenciado en Letras \\
\hline $\begin{array}{c}\text { Diplomada Sciences Po. Escuela } \\
\text { de Periodismo por el CFJ }\end{array}$ & Escuela de Periodismo CFJ & $\begin{array}{c}\text { Licenciado en Letras. Escuela de } \\
\text { Periodismo CFJ }\end{array}$ \\
\hline
\end{tabular}

En los editorialistas hay una cohesión y un sentimiento de comunidad: destacándose las afinidades generacionales, y aún más las culturales (estudios) y sociales (orígenes) que pueden, en algunos casos, acentuar la connivencia y proximidad entre sus pares.

\subsection{Género}

El universo de los editorialistas de la prensa nacional francesa es marcadamente masculino. Entre los editorialistas de la muestra solamente hay una mujer, Sylvie Kauffman, ex directora de la redacción de Le Monde. Un caso excepcional (denominado "efecto lupa"), en un diario que no acogió a una periodista en la sección de política hasta 1974 (en Le Figaro fue en 1977). Dobla en capital escolar a sus colegas editorialistas al poseer dos titulaciones más prestigiosas que las de sus homólogos: diplomada en Ciencias Políticas y también por una Escuela de Periodismo de renombre, CFJ, además de su capital social (hija de un médico militar). Entre otras experiencias que refuerzan su posición destaca una dilatada carrera como corresponsal en el extranjero. Kauffman, es actualmente directora editorial junto a otros dos editorialistas, que ocupan las mismas funciones que ella: Alain Frachon y Gerard Courtois, entrevistados para este trabajo de investigación. En el panel de editorialistas de Le Figaro no figura ninguna mujer (fácil de comprobar al firmar los editoriales). En el caso de Libération, ningún director adjunto -que implica la realización de la labor editoriales mujer.

La feminización progresiva de la profesión en Francia (de 19,5\% en 1974 a 44,9\% en 2012) no ha conllevado por el momento el acceso de mujeres periodistas a la tarea editorial. Un fenómeno que sus propios protagonistas descubren con sorpresa. Para François Sergent de Libération entre las razones que pueden explicar esta ausencia figuran el que los dueños de los medios sean, a su vez, hombres, y quizás la cuestión de la disponibilidad de horarios. "Es cierto que en la historia de Libération nunca ha 
habido mujeres editorialistas. Para un diario que se presenta como moderno y progresista! No está bien. Habrá que preconizar la discriminación positiva".

La única editorialista, Sylvia Kauffman se sorprende ante la pregunta:

“No hay? Lo ignoraba. Ahora que me lo dices es verdad. No tiene por qué ser así. Lo que veo es que hay una gran dificultad a que las mujeres accedan a puestos de responsabilidad. Y es así en todo el mundo, no solamente en Francia. Yo tengo una tendencia a decir que las mujeres prefieren las cosas concretas. Prefieren ser jefe de sección que redactoras jefes porque se ven más los resultados de su esfuerzo. Además el ejercicio de poder es menos conflictivo. Cuando eres redactor jefe hay que hacer más política, hay que ser estratega. $\mathrm{Y}$ a las mujeres les interesa menos eso. Las mujeres aman el periodismo pero no organizar el periodismo".

Si en los trabajos sobre la élite periodística (Rieffel, 1981; Santos-Sainz, 2001) la escasa presencia de mujeres ya había sido señalada, la crema de esta élite, cuya representación serían los editorialistas, refuerza aún más la inaccesibilidad a este círculo de elegidos. El oficio de editorialista sigue siendo un coto vedado para las mujeres periodistas.

Esta ausencia puede conllevar que determinadas posiciones en la defensa de la causa femenina se vean resentidas o sean inexistentes en la línea editorial. La editorialista de Le Monde reconoce que la posición de su diario es floja respecto a la batalla a favor del feminismo:

"Yo intento defenderlo pero no tengo apoyos. Me siento un poco aislada. Es una batalla que no es considerada prioritaria en la línea editorial. Es una pena, porque además sabemos que tenemos un problema de falta de lectores femeninos y los servicios de venta y marketing nos lo comentan a menudo. Creo que Le Monde es el periódico con mayor presencia de lectores hombres de la prensa cotidiana francesa. Tenemos que hacer esfuerzos y abrirnos más".

Más optimista sobre la cuestión, su homologo Gérard Courtois cree que pronto va a cambiar este fenómeno ya que cada vez hay más mujeres periodistas en Le Monde con responsabilidades en la redacción. "En el servicio político en los años 80 solo había una mujer, a partir del año 2000 es paritario. Ya no va a ser un territorio reservado a los hombres".

\subsection{Generaciones}

Sin relevo generacional. Respecto a la cuestión generacional se constata la escasa apertura a editorialistas más jóvenes. El universo de los editorialistas es un club cerrado a las nuevas generaciones. La ausencia de un pluralismo generacional, según un principio de homología de posiciones, puede conllevar una lectura diferente de la actualidad (Kaciaf, N., 2013). Las nuevas generaciones de periodistas políticos se interesan más en introducir nuevos tratamientos de la política, añadir nuevas temáticas y otros enfoques de la actualidad. La función de editorialista quizá refuerza el fenómeno de ser un bastión de periodistas experimentados, veteranos, ya que la mayoría sobrepasa la cincuentena. Tanto Le Monde como Le Figaro comparten editorialistas de la misma generación forjados, en su mayoría, profesionalmente en la misma re- 
dacción. Una selección de "movilidad interna" que responde a la confianza otorgada por la dirección a estos periodistas con una sólida y experimentada carrera periodística a sus espaldas.

\begin{tabular}{|c|c|c|}
\hline \multicolumn{3}{|c|}{ Cuadro 3. Edades de los editorialistas } \\
\hline Le Monde & Libération & Le Figaro \\
\hline 62 & 48 & 63 \\
\hline 56 & 50 & 54 \\
\hline 56 & 52 & 54 \\
\hline
\end{tabular}

El diario Le Monde concentra las edades más avanzadas, sobrepasando algunos los 60 años (Ver cuadro 3).

De sus tres editorialistas, dos comparten la misma trayectoria profesional como corresponsales en el extranjero. Respecto a Le Figaro, la media de edad ronda los 60 años al igual que sus homólogos de Le Monde. La mayoría de sus editorialistas han sido seleccionados siguiendo el criterio de movilidad interna en el seno de la misma redacción.

A diferencia de los otros diarios, en Libération, sus editorialistas son los más jóvenes entre los tres diarios de referencia analizados. Dos de ellos responden a la movilidad externa, con puestos de responsabilidad en el medio audiovisual, un trampolín para las nuevas generaciones. Sylvain Bourmaud, representaría el benjamín del equipo editorial con 48 años, y el resto no llega a los cincuenta. Su selección como editorialista responde a su nominación jerárquica como director adjunto, función que conlleva de manera subsidiaria la realización de editoriales. Una selección por cooptación que él mismo reconoce sin tapujos a la llamada del actual director, Nicolas Demorand.

Otros factores evocados por los editorialistas para explicar la ausencia de relevo generacional en sus funciones destacan "la falta de confianza" o "falta de tiempo", cierta "incultura política", "mayor gusto por el comentario que por el análisis" o "falta de espíritu colectivo". Algunos de los editorialistas de Le Monde son los que formulan más reparos. En la historia del diario se pueden encontrar algunas claves para entender la reticencia al relevo. Por ejemplo, Le Monde ha introducido tardíamente el editorial, a partir de 1995, sustituyendo a su tradicional boletín del extranjero. Es un diario que no ha tenido una tradición de editorialistas como Le Figaro. Y desde que en 1995, Colombani introdujo el género se confió a los periodistas más veteranos. Por eso Gérard Courtois explica que:

"Tenemos un problema técnico y es que somos muy pocos los que escribimos editoriales. Nuestra misión es asegurar el ejercicio editorial que antes se confiaba a los jefes de sección o redactores jefes. No veo un relevo inminente. Y creo que esto va a ser un verdadero problema que tendrá que solucionar el próximo director. Hay algunos periodistas que cuando les pedimos un borrador de editorial dicen que no tienen tiempo. A las nuevas generaciones no las veo muy interesadas en escribir editoriales. Se necesita demostrar, buscar argumentos. No es lo mismo escribir un editorial de Le Fígaro de 2000 signos que el de Le Monde con 3200". 
La legitimidad que otorga una extensa experiencia profesional, es el argumento evocado por Sylvie Kauffman para explicar la ausencia de editorialistas más jóvenes:

"Tras treinta años de experiencia profesional se tiene una cierta distancia al analizar los acontecimientos. Es verdad que llegar a ser editorialistas, responde al final de una carrera y creo que esto es benéfico. Es la sabiduría que ofrece la experiencia".

\section{Percepción del Rol}

¿Cuáles son las representaciones que tienen los editorialistas de su rol?, ¿Y de sus competencias? ¿Cuáles son sus referencias ideales? ¿Qué imagen o percepción tienen de sí mismos?

Se pueden establecer dos tipologías en el discurso que los propios editorialistas tienen de su rol y representación en el seno del diario. Por un lado, estarían los que consideran que el género está en declive, opción más minoritaria y representada por los más veteranos. Esta corriente mantiene que hay una devaluación de la palabra del editorialista y un contexto histórico poco proclive a las confrontaciones ideológicas. Consideran que ya no tienen el poder del magisterio y de influencia de otras épocas.

Alain Frachon, editorialista de Le Monde y exdirector de la redacción, encabeza el discurso más escéptico respecto a la pérdida de influencia del rol de editorialista:

"Los sondeos que hemos realizado demuestran que cada vez se leen menos. Por ejemplo, en la portada del periódico en su versión digital no aparece el editorial. Figura como uno de los artículos menos leídos. La influencia es menor que en otras épocas. Estamos en una época rebelde a los maîtres à penser. Hay una pérdida del magisterio. La irrupción de Internet ha supuesto un inmenso fórum de debates permanentes donde tu opinión no cuenta más que la de los no periodistas. Todo vale. Ya no hay fronteras en el mundo de la opinión. Quizás esto se va a estructurar dentro de unos años. En su opinión, en la actualidad para que un tema entre en la agenda mediática y en la política hay que perseverar: hay que insistir en un tema con 2 o 3 editoriales para obtener un eco".

La multiplicación de los comentarios en los diversos medios les hace pensar que sus reflexiones quedan más diluidas que en otros periodos cuando la voz de los editoriales de la prensa escrita dictaban la opinión. "Antes los medios seguían los menús ideológicos, hoy la opinión se ha diluido, hay menos debates. El electorado se ha dispersado. La gente compra diferentes medios, ya no hay tanta fidelidad a una cabecera. Los periodistas han perdido el monopolio de la palabra y el comentario. Hoy el oficio se ejerce de otra manera, hay infobesidad y publico sobreinformado", comenta Alain Frachon. Así apuntan a una inflexión provocada por el límite a su influencia. Según F. Sergent de Libération:

"Yo no me veo derrumbar un gobierno u influenciar un ministro. Nuestro objetivo es más de intentar abrir el debate, explicar, preguntar, analizar, y también comprometerse, ya que nosotros lo firmamos. Hoy existe menos el tono de acusación de otras épocas".

El contexto histórico explica, en opinión de esta corriente, que hoy no estemos frente a debates políticos cruciales como en épocas anteriores, como socialismo frente comunismo o la independencia de Argelia. Es más, consideran que en la actualidad los debates se dirigen más a cuestiones de sociedad que a verdaderas diatribas y diver- 
gencias ideológicas. Alain Frachon apunta de nuevo a la ausencia de grandes debates. Por eso añade que esta no es una época proclive a los editorialistas.

En contrapartida, el resto de editorialistas creen que siguen jugando un rol importante en los medios, incluso consideran más relevante su papel ya que precisamente el desafío del editorial hoy es mayor por la complejidad de la época en la que vivimos. Sylvie Kauffman, es quien mejor encarna esta postura del "renacimiento del editorial":

"Creo que hoy el editorial retoma un lugar muy importante frente a un contexto de dispersión de la información. Hemos pasado por una fase donde todo explotó y todo el mundo podía ser periodista u editorialista. Fue con el nacimiento de los blogs y la proliferación de tertulias, etc. Ahora estamos en una fase donde la gente está saturada, un poco perdidos y necesitan una selectividad. Necesitan que les ayudemos a elegir. No se puede seguir a 120 editorialistas por día. No se puede dar abasto y absorber toda la información y opinión que se ofrece. Y en esta reselectividad, nuestro editorial, el de un medio asentado, el de una cabecera prestigiosa, emerge con más fuerza. Nosotros somos un diario centrista, resultado de un consensus tras opiniones diversas".

En la misma línea de reevaluación actual del editorial responde Yves Thréard de Le Figaro, quien va más lejos al considerar que el editorialista forma parte de la vida política:

"La prensa de opinión como Libération y Le Figaro dan una gran importancia al editorial. Es nuestro color. Es su valor añadido. En el caso de Le Monde, es menos, ya que resulta más neutro. Precisamente frente a la falta de nitidez producida por la abundante información en continuo, el editorial permite poner en perspectiva un acontecimiento. No creo que haya declive, al contrario. El editorial da orientaciones a la gente. La prensa escrita francesa tiene una gran tradición como prensa de opinión, más que en los países anglosajones".

Todos los editorialistas coinciden en ver como un oficio específico la tarea editorial, a la que consagran cien por cien de su trabajo, salvo en el caso de Libération. La excepción de este diario resulta por ser una función pareja a la de director adjunto y que conlleva asumir otras tareas de dirección. En este sentido, el discurso cambia ya que no es una tarea asumida libremente y por convicción. Sylvain Bourmaud es quien expresa mejor este sentimiento:

"Yo no me considero editorialista, sino más bien periodista. Para mi editorialista no es un oficio, sino una función que me ocupa un cinco por ciento de mi trabajo de periodista como director adjunto. Somos cuatro directores adjuntos y cada día uno toma las riendas de la dirección del diario y debe escribir su editorial".

Si S. Bourmaud se considera ante todo periodista más que editorialista, es el único entre sus colegas entrevistados en señalar el papel de Intelectual de los medios: "Creo que un editorialista es un intelectual de los medios. Pero a veces hay que resistir a dar su opinión sobre todo". Sin embargo, otros colegas como F. Sergent de Libération rebaten esta idea:

"Yo me considero periodista y no un intelectual, aunque hago un trabajo intelectual. Yo creo que un intelectual tiene otra temporalidad de reflexión, no necesita producir todos los días. Pero ya no existen figuras como Camus o Malraux, eran épocas diferentes. Salvo Ber- 
nard Henry Lévy o Alain Finkielkraut, ya no existen. La gran época de los intelectuales responde a un periodo donde dominaba solamente la prensa escrita. Era su única tribuna. Hoy la televisión o la radio solamente buscan la palabra del experto".

\subsection{Cualidades y funciones}

Respecto a las competencias que debe poseer un editorialista la mayoría coincide en dar una gran relevancia a los elementos fundamentales del editorial como son la tesis y la argumentación. Un dominio que se adquiere, según apunta Gérard Courtois, con el ejercicio práctico del editorial:"es como cuando se hace gimnasia. Hay que entrenarse. En el editorial hay una retórica que si uno se entrena en este tipo de escritura sale naturalmente la argumentación". Como segunda cualidad destaca la memoria, otra de las funciones del editorial: "contextualizar, dar los antecedentes". En este sentido, para Vincent Giret, las misiones de un editorialista resaltan en primer lugar contextualizar, luego clarificar y después dar una opinión.

Sylvie Kauffman subraya entre las cualidades de un editorialista su espíritu abierto tanto políticamente como intelectualmente, y en especial su curiosidad:

"A menudo escribimos sobre temas muy diferentes. A veces puede ocurrir que escribamos sobre temas en los que no somos expertos. Hay que tener la humildad de buscar la información. Para mí la principal calidad de un editorialista es la honestidad intelectual. El editorialista no es un militante. Es alguien que pone sus conocimientos al servicio del lector. Lo resumiría en dos palabras: abierto y honesto".

\begin{tabular}{|c|c|c|}
\hline \multicolumn{3}{|c|}{ Cuadro 4. Cualidades principales de los editorialistas } \\
\hline Le Monde & Libération & Le Figaro \\
\hline Memoria/Análisis & Ideas/Opinión & Orientar/Opinión \\
\hline Practica & Humanista & Sintetizar \\
\hline Argumentación & Practica/Estilo & Estilo \\
\hline
\end{tabular}

Entre otras cualidades que destacan figuran poseer recursos intelectuales y el ser pedagógicos (Ver cuadro 4). Se une otra creencia de la mitología profesional: para ser editorialista hay que tener una pluma, una cualidad solamente citada por uno de los editorialistas de Le Figaro que considera como condition sine qua non el tener un estilo de escritura.

\begin{tabular}{|c|}
\hline $\begin{array}{c}\text { Cuadro 5. Funciones del } \\
\text { editorialista }\end{array}$ \\
\hline Orientar/ Misión pedagógica \\
\hline Analizar/ Contextualizar \\
\hline Argumentar/Opinar \\
\hline
\end{tabular}

Si nos remitimos a las formulaciones clásicas de las funciones del editorial según el periodismo americano (explicar los hechos, contextualizar, predecir el futuro y formular juicios u opiniones) la mayoría destacan tres funciones: analizar, contextualizar, argumentar y dar opiniones. Ninguno ha hecho referencia a la función de aviso meteorológico que puede dar un editorial al predecir el futuro (Ver cuadro 5).

La percepción que tienen los editorialistas entrevistados del tipo de editoriales que publican coincide en dar a Libération y Le Figaro un rol de prensa más de opinión que 
Le Monde, donde las ideas ocupan un primer lugar. En el caso de Le Monde, lo deja muy claro Alain Frachon: "no somos un periódico de editoriales, los nuestros son más analíticos, o de tipo interpretativo. Raras veces fijamos una opinión".

\begin{tabular}{|c|c|}
\hline \multicolumn{2}{|c|}{$\begin{array}{l}\text { Cuadro 6. Según el estilo de solicitación de } \\
\text { opinión }\end{array}$} \\
\hline Le Monde & Analítico/Interpretativo \\
\hline Libération & Polémico/Opinativo \\
\hline Le Figaro & Polémico/Interpretativo/Opinativo \\
\hline
\end{tabular}

Los editorialistas de Libération asumen su rol de escribir editoriales más de opinión, a veces polémicos, y Le Figaro, se sitúan en el estilo polémico, más en temas nacionales y a veces, asumen un estilo más interpretativo, en asuntos internacionales (Ver cuadro 6).

\subsection{Secretos de fabricación}

Entre los secretos de fabricación, Sylvain Bourmaud reconoce la importancia de tener las buenas fuentes y sobre todo recurrir a especialistas de confianza:

"A menudo llamo a mis amigos investigadores con el fin de verificar los argumentos del editorial. El editorial es una sola hoja. Es muy corto, una idea. Siempre hay la preocupación de la forma. Tiene que fijar claramente posiciones, lacónico, etc. Intento ser lo más preciso posible, seco, bastante clínico, frio".

Algunos de los editorialistas entrevistados reconocen con humildad que a veces tienen que escribir editoriales sobre temas que no dominan. Un obstáculo que superan documentándose y hablando con las fuentes expertas del tema. Luego reconoce que el dominio de la escritura del editorial le facilita la tarea.

Las dos cabeceras de opinión, Le Figaro y Libération comparten los mismos imperativos de tener un espacio editorial muy reducido. Para Yves Théard de Le Figaro: " La escritura del editorial debe conllevar un tono incisivo. Un estilo de texto corto, comprensible. Permite recrear el pensamiento". Pierre Rousselin comenta que realiza una media de tres editoriales sobre política exterior por semana dependiendo de la actualidad. Se queja de que cada vez son más cortos y que la sintonización resulta una tarea difícil. Confiesa que cuando escribe se mete en la piel del diario, en su punto de vista para así buscar sus argumentos. "Es un trabajo muy artesanal", añade el editorialista de Le Figaro. Rousselin realiza una clasificación de los editoriales: los de opinión, en su mayoría sobre la política en Francia, y los editoriales más analíticos, particularmente en economía e internacional (Ver cuadro 7).

\begin{tabular}{|c|c|c|}
\hline \multicolumn{3}{|c|}{ Cuadro 7. Principales fuentes de los editorialistas } \\
\hline Le Monde & Libération & Le Figaro \\
\hline Prensa internacional & Prensa francesa & Prensa francesa \\
\hline Prensa económica/internacional & Prensa económica & Prensa económica \\
\hline Prensa francesa/internacional & Prensa internacional & Prensa internacional \\
\hline
\end{tabular}

Los editorialistas de Le Monde reivindican su singularidad en el paisaje mediático francés de no firmar los editoriales. Así evoca Gérard Courtois esta fórmula que junto a sus colegas del diario asumen sin tapujos: 
"El editorial no firmado es un poco como un apostolado, el escaparate ideológico del diario. Nos obliga a estar atentos y ser honestos para buscar verdaderamente la opinión del periódico, por eso hay más cooperación y concertación con la redacción. Sentimos en nuestras espaldas la reflexión de la colectividad. Algo que tranquiliza pero que nos hace ser más exigentes. Nuestra tarea editorial está más adosada a la redacción porque tras el anonimato se erige la línea editorial del diario".

Para su homóloga, Sylvie Kaufman "el no firmar los editoriales les entronca con la tradición europea de los grandes diarios de referencia, ante los cuales compartimos la comunidad de valores. Es un signo de fuerza, es la opinión de toda la redacción y da seguridad".

El trabajo de los editorialistas de Le Monde está abierto a los debates con los responsables de las secciones implicadas. Así lo han hecho valer los tres editorialistas entrevistados, que se refieren permanentemente a su trabajo colectivo más que los otros editorialistas de los diarios donde se firman los editoriales.

\section{Influencia}

¿Qué representación tienen los editorialistas del papel que juegan? ¿Creen que tienen una cierta influencia? Y, ¿sobre quién? ¿Influencia sobre la agenda mediática o respecto a la agenda política?, Y, ¿sobre la opinión pública? Si las opiniones son divergentes respecto a la agenda política, sin embargo todos los editorialistas coinciden en que la influencia sobre la opinión pública es menor que en otras épocas. El recuerdo del justo resultado del voto favorable en el referéndum sobre el Tratado de Maastricht, cuando todos los editorialistas compartieron la misma línea editorial al hacer campaña a favor, dejó latente su escasa influencia en la opinión de los ciudadanos.

La mayoría de los editorialistas acuerdan mayor influencia en la agenda de los otros medios de comunicación que retoman los temas y puntos de vista tratados en sus editoriales. Para Pierre Rousselin:

"Los editoriales tienen una gran influencia. Somos jueces y parte. Alimentamos los debates políticos. La radio a menudo recoge nuestros editoriales. La toma de postura de nuestro diario es citada por los otros medios. La prensa escrita tiene la influencia sobre los otros medios que desempeñan un rol menor de análisis. Yo creo que tenemos mayor influencia en la agenda de los medios que sobre la agenda política”.

Un punto de vista con el que coincide F. Sergent: "Los editoriales de la prensa escrita están muy presentes en todas las televisiones y en las radio con información continua". De la muestra entrevistada quien defiende la postura de la influencia que ejercen sobre la agenda política es Yves Thréard de Le Figaro:

"El editorial ejerce una influencia sobre la clase política. Así mismo, el editorialista forma parte de la vida política. El editorialista evoca el ejemplo de la influencia que ha podido ejercer la línea editorial de Le Figaro respecto al Mariage pour tous, al final el gobierno irá menos lejos de lo previsto en relación a la filiación”.

Frente a la tradición anglosajona de no firmar los editoriales (como ocurre también en España) Francia mantiene su singularidad en esta materia, ya que salvo Le Monde, 
las otras dos cabeceras siempre los firman. Sus editorialistas comparten este criterio de firmar sus editoriales y no se plantean en ningún caso lanzar un debate para que se publiquen sin firma. El único que tuvo un debate sobre la cuestión fue Le Monde, pero la cuestión fue zanjada al ofrecerles crónicas semanales en el diario.

\subsection{El auge del comentario: los Editocrates}

Todos los editorialistas entrevistados coinciden en señalar el apogeo de los llamados éditocrates (Chollet, 2009), entre los que se encuentran algunos editorialistas y columnistas de los semaraios (llamada en Francia prensa magazine), de la radio, y de la televisión. Entre esta categoría apenas si figuran los editorialistas de los diarios de referencia. Esta tendencia de multiplicación de opiniones en diversas tribunas mediáticas ha provocado una amalgama terminológica producida con la denominación de editorialistas a todos aquellos que intervienen con sus opiniones en los medios audiovisuales.

Esta confusión entre la categoría de los que serían simplemente comentaristas frente a los verdaderos editorialistas de la prensa escrita desata las críticas de estos últimos. Pierre Rousselin coincide en calificar de inflación de los comentarios, aunque siempre ha habido opinian makers. Señala la emergencia de Internet con los blog, que refuerza aún más el fenómeno:

"El prestigio de un periódico como Le Figaro, con la reputación que goza, hace que sus opiniones editorializantes sean tomadas en cuenta. Un editorial de la prensa escrita tiene más influencia que la opinión de un bloguero, ya que es la opinión del diario. Para mi hay una gran diferencia entre los comentaristas y los editorialistas. Un comentarista da únicamente su opinión, el valor añadido de los editorialistas es que trabaja con todos los argumentos para ir a buscar los de su diario".

La mayoría de los editorialistas atacan la omnipresencia de los editocrates invitados a hablar de todo y de nada. F. Sergent precisa: "No es lo mismo nuestro trabajo en el que hay un tiempo para reflexión, para documentarse. Estos comentaristas realizan reflexiones fugaces en la televisión o en la radio, mezclada a veces con bromas y deslices graciosos. Este tipo de tertulias no tienen ningún interés". Quien se muestra más categórico de este fenómeno en auge es Alain Frachon:

"Pienso que la sobreexposición de los editorialistas, de los redactores jefes o directores de diarios, o de la prensa magazine en la radio o en la televisión quita una parte del misterio, una parte de la discreción. Creo que si se borra la singularidad de la prensa escrita transformando sus editorialistas en comentaristas desaparece su autoridad. El "charme" de los editorialistas es el anonimato. Los grandes dirigentes y editorialistas de la prensa de referencia en Europa como Spiegel o The Economist permanecen en el anonimato. Igual pasa con los grandes dirigentes de la economía mundial, permanecen también invisibles. Creo que a los que tienen una verdadera autoridad, un poder, nunca se les ve".

El deslizamiento editorializante de algunos programas de radio y televisión es un fenómeno percibido como negativo por la mayoría de los editorialistas de estos diarios entrevistados. Alain Frachon resume una opinión compartida por la mayoría de ellos: "En este tipo de tertulias lo que prevalece es el duelo, la pelea dialéctica y ha- 
blar por hablar. Apenas si hay una verdadera reflexión seria". Solamente aquellos que participan en tertulias en la televisión o en la radio, como es el caso de Yves Thréard, defienden la implicación en diversas tribunas: "La presencia de editorialistas en la radio y en la televisión permite valorizar y promocionar el escrito en los medios audiovisuales. Yo creo que esta visibilidad es positiva. Es una marca de la confianza que nos otorgan".

\subsection{Periodistas de referencia}

Se puede vislumbrar una cierta admiración de algunos de los editorialistas por los periodistas de renombre ligados al diario donde escriben. Hay una fuerte transmisión periodística, sintiéndose herederos de las grandes plumas de sus diarios. Así no es de extrañar que los editorialistas de Le Monde evoquen la figura mítica de Viasson-Ponté o del fundador Beuve-Méry, incluso cuando rememoran la historia más reciente citen a Jean-Marie Colombani, ex director de Le Monde. La única mujer editorialista evoca figuras del pasado, ya desaparecidas y evita citar nombres de periodistas actuales, solamente enumera los diarios de referencia. Hay igualmente una diversidad ideológica entre los periodistas de referencia mencionados, en el caso de Frachon y Courtois, citando desde Jean Daniel (Le Nouvel Observateur) hasta Philippe Tesson de Le Figaro. Unicamente Frachon de Le Monde rememora periodistas ya desaparecidos, figuras míticas de la historia del periodismo galo como Aron, Mauriac o incluso Françoise Giroud (Ver cuadro 8).

\begin{tabular}{|c|c|c|}
\hline \multicolumn{3}{|c|}{ Cuadro 8. Periodistas de referencia de los editorialistas } \\
\hline Le Monde & Libération & Le Figaro \\
\hline Figuras míticas desaparecidas & Le Monde & Editorialistas prensa magazine \\
\hline Editorialistas prensa magazine & Nouvel Obs/ Le Point & Figuras míticas desaparecidas \\
\hline Prensa referencia internacional & France Culture & Prensa referencia internacional \\
\hline
\end{tabular}

Por su parte, los editorialistas de Libération hacen referencia únicamente a periodistas actuales y en su mayoría de medios con una línea editorial de centro-izquierda. Las excepciones son F. Sergent de Libération, que cita a Pierre Rousselin de Le Figaro, quien realiza editoriales más analíticos sobre temas internacionales, y Vincent Giret, que cita a Claude Imbert (Le Point).

\section{El futuro del editorial}

Las dos corrientes de opinión sobre el estado actual del editorial coinciden en compartir una visión optimista respecto a su futuro. Los hay que creen que esta fase de reubicación y de auge del editorial ya ha sido ganada frente a la confusión que provoca la proliferación de comentarios en todos los medios. Si algunos, por el contrario, piensan que esta etapa aún no ha llegado, y que todavía hay un cierto declive, sin embargo opinan que se va a estructurar. Quien mejor representa una visión esperanzadora de la misión del editorial es Sylvie Kauffman. Ella vislumbra un lugar aún más preponderante debido a la saturación de los ciudadanos ante tanto exceso de información: "Respecto a su invisibilidad en la versión digital de Le Monde, considera que responde a la política de Internet de poner en un primer plano la información más que la opinión”. 
En la misma línea, Yves Thréard: "Creo que habrá todavía más lugar para el editorial. Es el futuro de la prensa escrita. Los editoriales animan el debate, ello permite a la prensa vivir. También permite dar el tono". Precisamente, en este nueva fase de reubicación y despegue del editorial conviene señalar su incorporación en un diario como Le Parisien (desde finales de 2013), que nunca antes había incluido editoriales.

Pierre Rousselin de Le Figaro considera que la prensa va a cambiar: "Tiene que convertirse cada vez más en una prensa de calidad, de análisis y de profundidad. La prensa escrita debe continuar por este camino de apostar por la calidad. Hay que dejar a Internet la reactividad".

F. Sergent también resalta su optimismo frente al futuro del editorial al que presagia una belle époque:

"La gente busca ahora un sentido a la actualidad, una jerarquía tras una época cargada por el exceso de los comentarios. Pero no está solo el editorial, también es importante la jerarquización de la información, la cabecera, la manera de tratar los acontecimientos. Creo que con tanta abundancia de fuentes la gente se pierde si no es periodista".

Vincent Giret cree que el editorial clásico se está disolviendo: "Cada vez tenemos más competencia de palabra con otros comentaristas. Antes solo existía el editorial de la prensa escrita, hoy hay opiniones por todas partes".

En la misma línea, Gerard Courtois califica a la época actual de ruidosa en los comentarios:

"Hay una especie de comentarios en permanencia en el debate público. Y esto pone de relieve al editorial consistente. Nosotros estamos en la reflexión, hay una demostración de los hechos, una argumentación, no tiene nada que ver con los comentarios instantáneos del momento. Es nuestra fuerza y nuestro futuro".

\section{Conclusiones}

1. Los resultados de este trabajo permiten destacar la importancia que juegan las predisposiciones sociales en la carrera profesional para alcanzar el puesto de editorialista. De los nueve editorialistas entrevistados todos pertenecen a un origen social favorecido, siendo fundamentalmente hijos de médicos, abogados o de directivos de empresas. Su universo se configura como un microcosmos donde todos comparten las mismas propiedades sociales: capital social, cultural y económico. La diversidad social es inexistente, lo que puede incidir sin duda en el pluralismo de opiniones y en su percepción del mundo. En este sentido, en Francia hay debates donde se plantean la necesidad de democratizar el acceso a la élite periodística, a la que pertenecen en su estrato más alto. Hay corrientes que promueven la necesidad de implantar medidas que desinhiban a determinadas clases sociales que piensan que la carrera de periodista no está destinada para ellos para así asegurar una democratización y apertura de la profesión (Marchetti, 2011).

2. En esta homogeneización tan elitista de los editorialistas confluye no solo la herencia familiar sino también el currículo académico, su alta cualificación con diplomas de nivel de máster y la diplomatura en gran parte de los casos por una prestigiosa escuela de Periodismo privada y parisina. 
3. El universo es exclusivamente masculino: los editorialistas son todos hombres, la única excepción es la editorialista de Le Monde, quien ha ocupado la función de directora la redacción.

4. Ala práctica inexistencia de mujeres se une el escaso relevo generacional, siendo la edad media en torno a los 60 años. Algunos editorialistas manifiestan una cierta desconfianza hacia nuevos perfiles que reemplacen su función.

5. La "retorica profesional" se apoya en un discurso con representaciones míticas asentadas fundamentalmente en la función pedagógica y en menor medida en el rol democrático, que se resumiría en afirmaciones como: "alimentamos el debate político" (editorialista de Le Figaro). Se sienten más periodistas que intelectuales mediáticos y resaltan entre las competencias de un editorialista su capacidad de argumentar, cultura, memoria, análisis, rigor, ideas, contextualizar, la práctica y en menor medida, la honestidad intelectual y la humildad, cualidades deontológicas evocadas únicamente por la mujer editorialista.

6. Sobre su influencia mantienen posiciones reservadas respecto al impacto sobre la agenda de política y a su rol de orientadores de la opinión pública, sin embargo creen que tienen mayor influencia en la agenda de los otros medios (radio y televisión). Hay dos corrientes: aquellos que consideran que el editorial está en declive ("vivimos en una época que no es proclive a los editorialistas ni a los "maîtres à penser"). Algunos consideran que el editorial se lee menos frente al auge y éxito de las tribunas de opinión, y por lo tanto creen que la influencia es menor que en otras épocas donde había grandes debates suscitados desde los editoriales. Por otro lado, estarían aquellos que defienden la reubicación del editorial frente a la infobesidad y al auge de los comentaristas en diversas tribunas mediáticas (denominados "editocrates").

7. Entre sus periodistas de referencia destacan las diferencias entre los editorialistas de Le Monde, que evocan más a la prensa de referencia internacional, frente a los de Le Figaro y Libération que citan a editorialistas franceses de la prensa magazine. Los de mayor edad nombran entre los editorialistas que les han marcado a figuras míticas del periodismo ya desaparecidas. Salvo los editorialistas de Le Monde, todos confiesan el seguimiento de los editoriales de algunos de sus homólogos a los que admiran.

8. Reivindican que la misión específica del trabajo de un editorialista en un diario de referencia es la de desarrollar todos los argumentos para ir a buscar los de su diario. Diferencian su trabajo reflexivo y argumentativo frente al comentarista que solo ofrece sus opiniones personales instantáneas. Todos ellos sienten un gran apego por la cabecera para la que trabajan, a la que consideran como una marca de prestigio y credibilidad. Resaltan su función como de una gran utilidad social, reconociendo el prestigio que les otorga el trabajo de auscultar la actualidad y el valor añadido que supone el editorial de un medio de referencia.

A veces algunos elaboran un discurso de auto justificación, que contribuye a propagar una visión encantada e ilusoria del universo periodístico. Así, los editorialistas que pertenecen a los diarios de opinión (Le Figaro y Libération) consideran que tienen más peso en la agenda de los medios, incluso en la agenda política reconociendo haber ganado algunas batallas políticas en determinados temas. Esta diferencia res- 
pecto al discurso de los editorialistas de Le Monde quizás se sustente por establecer editoriales más opinativos frente a los más analíticos de Le Monde. Los editorialistas de Le Monde, defienden la tradición de no firmar y algunos reivindican la autoridad que les da su anonimato, sintiendo una mayor responsabilidad por llevar a sus espaldas el peso de la colectividad del diario y de su línea editorial. En sus rutinas periodísticas los editorialistas de Le Monde incorporan una mayor colaboración con la redacción (consultas, documentación, elaboración de borradores) que sus homólogos de Libération y Le Figaro.

9. Por último, señalar que si aplicamos la noción de habitus de Bourdieu al microcosmos de los editorialistas, quizás en parte podría ayudarnos a comprender, entre otros aspectos, su predisposición a preservar la reproducción de su universo - criterios de selección, así como una cierta reticencia al relevo generacional y a la apertura social- y la tendencia progresiva de la homogeneización de los contenidos periodísticos que producen basados más en la reproducción del sistema, conformismo, que a su transformación o cambio (Watine, 1999).

\section{Referencias bibliográficas}

ALBERT, Pierre (2004): La presse française. Paris, La Documentation française.

AUBESNAS, Florence et BENASAYAG, Miguel (1999): La fabrication de l'information, Paris, La Découverte.

AUBESNAS, Florence (2009): Petite conférence sur le journalisme. Paris, Bayard.

BAKER Keith Michael (1993): Le tribunal de l'opinion. Paris, Payot.

BARRÉ, Jean-Louis (dir. 2008): François Mauriac. Journal. Mémoires politiques. Paris, Robert Laffont.

BERGER, Peter et LUCKMANN, Thomas (1994): La construction sociale de la réalité. Paris, Méridiens-Klincksieck.

BLANDIN, Claire (2007): Le Figaro. Deux siècles d'histoire. Paris, Armand Colin.

BOURDIEU, Pierre et PASSERON, Jean-Claude (1970): La reproduction. Paris, Minuit.

BOURDIEU, Pierre (1982): Ce que parler veut dire. Paris, Fayard.

BOURDIEU, Pierre (1996): Sur la télévision. Paris, Raisons d'agir.

BOUVERESSE, Jacques (2003): Schmock ou le triomphe du journalisme. Paris, Seuil.

BRETON, Philippe (2000): La parole manipulé. Paris, La découverte.

BUXTON, David et JAMES, Francis (dirs. 2005): Les intellectuels des médias. Paris, L'Harmattan/INA.

CARTON, Daniel (2003): Bien entendu ... c'est off. Paris, Albin Michel.

CAYROL, Roland (1997): Médias et Démocratie. Paris, Presses de Sciences Po.

CHAMPAGNE, Patrick (1984): "La manifestation. La production de l'événement politique”. Actes de la Recherche en Sciences Sociales, vol. 52, núm. 52-53, pp. 1941. 
CHAMPAGNE, Patrick (1990): Faire l'opinion. Le nouveau jeu politique. Paris, Minuit.

CHARLES, Christophe (2004): Le siècle de la presse (1830-1939). Paris, Seuil.

CHARON, Jean-Marie (2006): "Les journalistes politiques: qui sont-ils?". Le temps des médias, 2, núm. 7, pp. 176-190.

CHARON, Jean-Marie (1991): Cartes de presse. Enquête sur les journalistes. Paris, Stock.

CHASTENET, Philippe (1986): Les divas de l'info. Paris, Le Pré aux Clercs.

CHOLLET, Mona; OLIVER, Cyran; FONTENELLE, Sébastien; et REYMOND Mathias (2009): Les éditocrates. Paris, La découverte.

COCULA, Bernard (2006): Mauriac, écrivain et journaliste. Bordeaux, Editions SudOuest.

CORCUFF, Philippe (2011): Les nouvelles sociologies. Entre le collectif et l'individuel. Paris, Armand Colin, collection " 128.

DAGNAUD, Monique (2000): L'État et les médias. Paris, Editions Odile Jacob.

DARRAS Éric (1995): "Le pouvoir "médiacratique". Les logiques de recrutement des invités politiques à la télévision”. Politix, vol. 8, núm. 30, pp. 183-198.

DELPORTE, Christian (1999): Les journalistes en France, 1880-1950. Naissance et construction d'une profession. Paris, Seuil.

EVENO, Patrick (2004): Histoire du journal. Le Monde 1944-2004. Paris, Albin Michel.

ESTIER, Claude (2011): Journalistes engagés. Paris, Cherche Midi.

FERENCZI, Thomas (1993): L'invention du journalisme en France. Paris, Plon.

KACIAF, Nicolas (2013): Les pages «politique». Histoire du journalisme politique dans la presse française (1945-2006). Rennes, Presse Universitaire de Rennes.

HALIMI, Serge (1998): Les nouveaux chiens de garde. Paris, Raisons d'agir.

HERMAN, Thierry et JUNFER, Nicole (2001): "L'éditorial, «vitrine idéologique du journal»", Semen, Revue de sémio-linguistique des textes et discours, [en ligne], 13, mis en ligne le 04 mai 2012. URL: http://semen.revues.org/2610

JULY, Serge; KAHN, Jean-François; et PLENEL, Edwy (2009): Faut-il croire les journalistes?. Paris, Editions Mordicus.

KOVACH, Bill et ROSENSTIEL, Tom (2003): The elements of journalism. New York, Three Rivers Press.

LACOUTURE, Jean (2009): Les impatiens de l'histoire. Grands journalistes français. Paris, Grasset.

LAZARSFELD, Paul L. et KATTZ, Elihu (2008): Influence personnelle. Ce que les gens font des médias. Paris, Armand Colin/INA. 
LE BOHEC, Jacques (1997): Les rapports presse-politique. Paris, L'Harmattan.

LEMIEUX, Cyril (2000): Mauvaise presse. Paris, Métailié.

LEMIEUX, Cyril (2010): La subjectivité journalistique, Onze leçons sur le rôle de l'individualité dans la production de l'information. Paris, Editions de l'EHESS.

LEVY, Élisabeth et COHEN, Philippe (2008): Notre métier a mal tourné. Paris, Mille et une nuit.

MAMOU, Ives (1991): C'est la faute aux médias. Paris, Payot.

MARCHETTI, Dominique et LAFARGUE, Géraud (2011): Les portes fermées $d u$ journalisme. L'espace social des étudiants des formations " reconnues ». Le Seuil | Actes de la recherche en sciences sociales, núm. 189.

MARTUCCELI, Danilo et DE SINGLY, François (2012): Les Sociologies de l'indi$v i d u$. Paris, Éditions Armand Colin, deuxième édition.

MAUDIT, Laurent (2007): Petits conseils. Paris, Stock.

MERCIER, Arnaud (dir., 2009): Le journalisme. Paris, CNRS Editions.

MERLANT, Philippe et CHATEL, Luc (2009): Médias. La faillite d'un contre-pouvoir? Paris, Fayard.

MUHLMANN, Géraldine (2004): Une histoire politique du journalisme. Paris, Puf.

MUZET, Denis (2006): La mal Info. Paris, L'aube.

NEVEU, Erik (2001): Sociologie du Journalisme. Paris, La Découverte.

PINTO, Evelyne (dir., 2007): Pour une analyse critique des médias. Paris, Éditions du Croquant.

POULET, Bernard (2009): La fin des journaux et l'avenir de l'information. Paris, Gallimard.

POULET, Bernard (2003): Le pouvoir du Monde. Quand un journal veut changer la France. Paris, La Découverte.

RAMONET, Ignacio (2011): L'explosion du journalisme. Des médias de masse à la masse de médias. Paris, Galilée.

RIEFFEL Rémy (1984): L'élite des journalistes. Paris, PUF.

RINGOOT, Roselyne et UTARD, Jean-Michel, (dirs. 2009): Les genres journalistiques. Savoir et savoir-faire. Paris L'Harmattan.

RIUTORT Philippe (1996): “Grandir l'événement. L'art et la manière de l'éditorialiste”. Réseaux, vol. 14, núm. 76, pp. 61-81.

ROCAUTE, Yves (1991): Splendeurs et misères des journalistes. Paris, CalmannLévy.

RUELLAN Denis (2011): Nous, Journalistes. Déontologie et identité. Grenoble, PUG. RUELLAN Denis (1993): Le professionnalisme du flou. Grenoble, PUG. 
RUFFIN, François (2003): Les petits soldats du journalisme. Paris, Les Arènes.

SANTOS-SAINZ, Maria (2005): L'élite journalistique et ses pouvoirs. Rennes, Apogée.

SERRE, Delphine (2012): "Le capital culturel dans tous ses états". Actes de la recherche en sciences Sociales, núm. 191-192, pp. 4-13. Paris, Seuil.

SCHNEIDERMANN, Daniel (1999): Du journalisme après Bourdieu. Paris, Fayard.

SCHNEIDERMANN, Daniel (2003): Le cauchemar médiatique. Paris, Denoël.

TAILLEUR, Jean-Pierre (2002): Bévues de presse. Paris, Le Félin.

TUNSTALL, Jeremy (1971): Journalists at work. London, Constable.

VOYENNE, Bernard (1985): Les journalistes français. D'où viennent-ils? Qui sontils ? Quels sont-ils ?. Paris, Cfpj.

WATINE, Thierry (1999): "Bourdieu et les médias: des lois du champ et de l'habitus comme présomptions du conservatisme des journalistes". Les Cahiers du Journalisme, núm. 6, octobre, pp. 126-151. 